\title{
Familial vs. sporadic sarcoidosis: BTNL2 polymorphisms, clinical presentations, and outcomes in a French cohort
}

\author{
Yves Pacheco ${ }^{1,11^{*}}$, Alain Calender ${ }^{2}$, Dominique Israël-Biet ${ }^{3}$, Pascal Roy $^{4}$, Serge Lebecque 5 , Vincent Cottin 6 , \\ Diane Bouvry ${ }^{7}$, Hilario Nunes ${ }^{7}$, Pascal Sève ${ }^{8}$, Laurent Pérard ${ }^{9}$, Gilles Devouassoux ${ }^{8}$, Nathalie Freymond ${ }^{1}$, \\ Chahira Khouatra ${ }^{6}$, Benoît Wallaert ${ }^{10}$, Raphaelle Lamy ${ }^{2}$, Mad-Hélénie Elsensohn ${ }^{4}$, Claire Bardel ${ }^{4}$, \\ Dominique Valeyre ${ }^{7}$ and GSF group
}

\begin{abstract}
Background: The occurrence of familial forms of sarcoidosis (OMIM 181100) suggests a genetic predisposition. The involvement of butyrophilin-like 2 (BTNL2) gene (rs2076530 variant) has to be investigated.

Results: The study performed independent analyses of BTNL2 polymorphism, clinical phenotypes, and outcomes in familial vs. sporadic presentations in 256 sporadic and 207 familial cases from 140 families. The logistic multivariate model showed that a young age at diagnosis and the combination of lung and skin involvement at diagnosis may distinguish sporadic from familial sarcoidosis ( $p=0.016$ and $p=0.041$ ). We observed also that Sarcoid Clinical Activity Classification (SCAC) profiles were significantly different between familial and sporadic cases $(p=0.0497)$. Variant rs2076530 was more frequent in patients than in controls (OR $=2.02 ; 95 \% \mathrm{Cl}$ : [1.32-3.09]) but showed no difference between sporadic and familial cases and no difference according to the clinical phenotype or the outcome.

Conclusion: Despite a significant difference in BTNL2 polymorphism between sarcoid patients and controls, there was no such difference between familial and sporadic sarcoidosis cases and no correlation between BTNL2 polymorphism and disease severity or outcome. Thus, BTNL2 difference cannot be considered as a key marker for disease classification or patient management.
\end{abstract}

Keywords: Sarcoidosis, Medical genetics, Human BTNL2 protein, Candidate gene association study, Classification

\section{Background}

Sarcoidosis is a rare multisystemic granulomatous disorder of still unknown origin. It has various presentations, severities, treatments, and outcomes [1]. Genetic studies have searched for polymorphisms associated with the risk of developing the disease and for genotypephenotype correlations. Among several candidate genes, BTNL2 (butyrophylin-like 2) has been intensively studied. A recent meta-analysis has confirmed that BTNL2 rs2076530 polymorphism contributes to the risk of sarcoidosis [2]. Meanwhile, it has been difficult to

\footnotetext{
* Correspondence: yves.pacheco@univ-lyon1.fr

'Hospices Civils de Lyon, Centre Hospitalier Lyon Sud, Université Claude

Bernard - Lyon 1, EA-7426, Lyon, France

${ }^{11}$ Université Claude Bernard Lyon 1 - EA-7426, 165 Chemin du Grand

Revoyet, F-69495 Pierre Benite, France

Full list of author information is available at the end of the article
}

investigate the clinical phenotypes and outcomes of sarcoidosis in search for genotype-phenotype correlations. Nevertheless, interesting suggestions about classical radiographic staging [3], factor analysis [4, 5], SCAC (Sarcoid Clinical Activity Classification) [6], and WASOG (World Association for Sarcoidosis and Other Granulomatous Disorders) clinical outcome status classification [7] are available.

We investigated BTNL2 gene in familial forms of sarcoidosis to assess the role of this gene as a major indicator of hereditary predisposition to the disease [8-10] and find out whether it can be a useful genetic marker for clinical management and prognosis. 


\section{Methods}

\section{Participant inclusion}

SARCFAM (a national project on familial sarcoidosis) is a prospective observational cohort study started in 2008. It involves 28 French university departments of internal medicine or pulmonology that care for sarcoidosis patients.

Three inclusion criteria were: i) clinical and paraclinical features consistent with sarcoidosis; ii) histopathological evidence of non-caseating granuloma, except Löfgren syndrome; and, iii) exclusion of any other chronic disease.

The evidence for non-caseating granulomatous lesions was obtained by mediastinoscopy (26.4\%), or bronchial/ pulmonary (34.9\%), accessory salivary gland (12.3\%), peripheral lymph node (10.4\%), skin (9.8\%), conjunctiva (2.5\%), kidney (1.2\%) or other (2.5\%) biopsies.

All 463 cases included were diagnosed according to the Joint Statement of the American Thoracic Society (ATS), the European Respiratory Society (ERS), and the (WASOG) [11]. The disease type (familial vs. sporadic) was determined by structured interview.

The control population for the genetic investigation consisted of 430 DNA samples from a single genetic database of healthy human reference population. The mean age (41.5 \pm 17.5 years) and geographic origins [European: $n=324(75.3 \%)$ and Sub-Saharan African plus Caribbean: $n=106(24.7 \%)]$ were quite similar to those of the study sarcoid patients.

\section{Clinical assessment}

All patients with sporadic sarcoidosis or index cases with familial sarcoidosis were diagnosed and followed-up in the 28 clinical centers. A specific case report form was filled in with demographic data, medical history, disease onset (symptomatic or asymptomatic), detailed organ involvement, treatments, and outcome. A detailed familial history of sarcoidosis was also examined to assess genetic predisposition. Familial cases were offered a DNA sampling and the related forms were filled in the center where the index case was diagnosed.

Clinical, biological, and imaging data were also collected at diagnosis and each follow-up visit until December 2012. These data included: i) chest X-ray staging (0: no involvement, 1: isolated hilar lymphadenopathy, 2: hilar lymphadenopathy with pulmonary infiltration, 3: isolated pulmonary infiltration without fibrosis, 4: pulmonary fibrosis); ii) pulmonary function testing: forced expiratory volume in one second (FEV1), forced vital capacity (FVC), FEV1/FVC ratio, and total lung capacity (TLC); iii) biological variables: serum calcium and creatinine, bronchoalveolar lavage cell count; and, iv) information about treatment: systemic treatment with corticosteroids or non-steroid immunosuppressive agents.
The disease outcome was examined using SCAC with six progression patterns [6] and, whenever possible, a classification of outcome in four categories: 1) recovery within 3 years; 2) recovery between 3 and 5 years; 3) no recovery at 5 years; 4 ) death.

\section{Genetic study}

Blood DNAs were obtained from nearly all patients and tested for BTNL2 gene rs2076530 polymorphism. Primer oligonucleotides for polymerase chain reaction and DNA sequencing were located within the reference sequence surrounding rs2076530, the major single-nucleotide polymorphisms (SNPs) that induce truncation of the BTNL2 protein [8]. A 490-bp amplicon was produced and sequenced using primers 5'-AATGCACAGAGC ATGGAGGTGAG-3' and 5' -GAAGATACTGGAAAAG ATACAAG-3'.

The quality control of PCR products was performed on a LabChipGX system (PERKIN ELMER ${ }^{\mathrm{TM}}$ ) and the products purified by NucleoFast ${ }^{\circledR} 96$ PCR Clean-up Kit from MACHEREY-NAGEL ${ }^{\mathrm{T}}$. The sequencing was performed by Big Dye terminator v1.1 after purification with BigDye XTerminator $^{\mathrm{Tm}}$ Purification Kit. Sequence delineation and base calling used an automated fluorescent DNA sequencer (Applied Biosystems ${ }^{\mathrm{Ts}}$, model 3130xl).

\section{Statistical analysis}

Familial and sporadic cases were compared using a generalized linear mixed model. To allow for family links, the model included correlations between patients' random effects [12].

In a first application of the model, univariate submodels were constructed and compared with a null model (model with intercept only) using a likelihood ratio test to test the effects of the main variables (Table 1). The clinical characteristics of BTNL2 G/G vs. BTNL2 A/A plus BTNL2 A/G genotypes were compared with the same method (Table 2). Because the study was mainly exploratory, only raw $p$-values are shown; however, a Bonferroni correction for multiple testing was applied and when raw $p$-values were significant, adjusted $p$-values were also calculated [13].

In another application, a multivariate model was built with the most important variables collected at diagnosis (age, sex, organs involved, chest X-ray stage, and BTNL2 polymorphism) to test their association with familial cases.

\section{Results}

\section{The study population}

Among the 463 patients, 256 presented with a sporadic disease and 207 belonged to 140 families (one patient from each of 85 families, two patients from each of 48 families, three patients from each of five families, four 
Table 1 Epidemiological, clinical, and biological characteristics of familial and sporadic sarcoid patients

\begin{tabular}{|c|c|c|c|c|c|}
\hline Data & Number & Familial cases & Sporadic cases & Univariate model raw $p$ value* & Multivariate model $p$ value \\
\hline \multicolumn{6}{|l|}{ Epidemiological data } \\
\hline N & 463 & $207(44.7 \%)$ & $256(55.3 \%)$ & & \\
\hline Sex & 463 & & & 0.49 & \\
\hline Male & 201 & $86(41.6 \%)$ & $115(44.9 \%)$ & & 0.20 \\
\hline Female & 262 & $121(58.4 \%)$ & $141(55.1 \%)$ & & Ref. \\
\hline Age at diagnosis & 424 & & & $0.001[0.021]$ & 0.016 \\
\hline Mean \pm SD & & $38.2 \pm 13.1$ & $43.0 \pm 15.5$ & & \\
\hline Median $[q 1 ; q 3]$ & & $35.5[29.3 ; 46.2]$ & $40.3[30.6 ; 54.0]$ & & \\
\hline Ethnicity & 303 & & & 0.85 & \\
\hline European & 235 & $112(77.2 \%)$ & $123(77.9 \%)$ & & \\
\hline Caribbean or Sub-Saharan African & 68 & $33(22.8 \%)$ & $35(22.1 \%)$ & & \\
\hline Smokers & 381 & & & 0.43 & \\
\hline Yes & 156 & $56(38.4 \%)$ & $100(42.6 \%)$ & & \\
\hline No & 225 & $90(61.6 \%)$ & $135(57.4 \%)$ & & \\
\hline \multicolumn{6}{|l|}{ Clinical data at diagnosis } \\
\hline Disease onset & 401 & & & $0.015[0.28]$ & \\
\hline Asymptomatic & 137 & $45(27.3 \%)$ & $92(39.0 \%)$ & & \\
\hline Symptomatic & 264 & $120(72.7 \%)$ & $144(61.0 \%)$ & & \\
\hline Löfgren syndrome & 378 & & & 0.26 & \\
\hline Yes & 58 & $29(17.8 \%)$ & $29(13.5 \%)$ & & \\
\hline No & 320 & $134(82.2 \%)$ & $186(86.5 \%)$ & & \\
\hline Number of organs involved & 414 & & & 0.144 & \\
\hline 1 & 158 & $69(39.9 \%)$ & $89(36.9 \%)$ & & \\
\hline 2 & 117 & $36(20.8 \%)$ & $81(33.6 \%)$ & & \\
\hline 3 & 70 & $29(16.8 \%)$ & $41(17.0 \%)$ & & \\
\hline$\geq 4$ & 69 & $39(22.5 \%)$ & $30(12.5 \%)$ & & \\
\hline Organs involved & 414 & & & $<0.001[0.003]$ & \\
\hline Lungs only & 148 & 68 (39.31\%) & $80(33.2 \%)$ & & 0.65 \\
\hline Lungs and Eyes & 53 & $10(5.78 \%)$ & $43(17.84 \%)$ & & 0.076 \\
\hline Lungs and Skin & 21 & $15(8.67 \%)$ & $6(2.49 \%)$ & & 0.041 \\
\hline Other organs & 192 & 80 (46.24\%) & $112(46.47 \%)$ & & Ref \\
\hline X-ray staging & 456 & & & 0.20 & 0.78 \\
\hline 0 & 68 & $40(19.8 \%)$ & $28(11.0 \%)$ & & \\
\hline 1 & 162 & $66(32.7 \%)$ & $96(37.8 \%)$ & & \\
\hline 2 & 157 & $69(34.2 \%)$ & $88(34.7 \%)$ & & \\
\hline 3 & 48 & $15(7.4 \%)$ & $33(13.0 \%)$ & & \\
\hline 4 & 21 & $12(5.9 \%)$ & $9(3.5 \%)$ & & \\
\hline \multicolumn{6}{|l|}{ PFT at first visit } \\
\hline TLC (\%) & 215 & & & 0.93 & \\
\hline$<80 \%$ & 47 & $18(22.2 \%)$ & $29(21.6 \%)$ & & \\
\hline$\geq 80 \%$ & 168 & $63(77.8 \%)$ & 105 (78.4\%) & & \\
\hline FEV1/FVC & 242 & & & 0.43 & \\
\hline$<70 \%$ & 55 & $18(20.0 \%)$ & 37 (24.3\%) & & \\
\hline
\end{tabular}


Table 1 Epidemiological, clinical, and biological characteristics of familial and sporadic sarcoid patients (Continued)

\begin{tabular}{|c|c|c|c|c|c|}
\hline$\geq 70 \%$ & 187 & $72(80.0 \%)$ & $115(75.7 \%)$ & & \\
\hline \multicolumn{6}{|l|}{ Biology at first visit } \\
\hline Bronchoalveolar lavage lymphocytes (\%) & 95 & & & 0.171 & \\
\hline$<10$ & 23 & $3(11.6 \%)$ & $20(29.0 \%)$ & & \\
\hline$[10 ; 20]$ & 17 & $5(19.2 \%)$ & $12(17.4 \%)$ & & \\
\hline$>20$ & 55 & $18(69.2 \%)$ & $37(53.6 \%)$ & & \\
\hline Calcemia & 256 & & & 0.80 & \\
\hline$<2.25$ & 52 & $21(22.6 \%)$ & $31(19.0 \%)$ & & \\
\hline$[2.25-2.5]$ & 182 & $64(68.8 \%)$ & $118(72.4 \%)$ & & \\
\hline$>2.5$ & 22 & $8(8.6 \%)$ & $14(8.6 \%)$ & & \\
\hline \multicolumn{6}{|l|}{ Treatment } \\
\hline Treatment & 463 & & & $<0.001[0.008]$ & \\
\hline None & 136 & 79 (38.2\%) & $57(22.3 \%)$ & & \\
\hline At least one & 327 & $128(61.8 \%)$ & $199(77.7 \%)$ & & \\
\hline Type of treatment & 327 & & & 0.188 & \\
\hline Corticosteroids only & 186 & $67(52.3 \%)$ & $119(59.8 \%)$ & & \\
\hline Other treatment & 141 & $61(47.7 \%)$ & $80(40.2 \%)$ & & \\
\hline \multicolumn{6}{|l|}{ Pattern of disease course } \\
\hline SCAC & 414 & & & $0.003[0.0497]$ & \\
\hline 1- symptomatic - no treatment & 48 & $30(18.1 \%)$ & $18(7.3 \%)$ & & \\
\hline 2- symptomatic - treatment $\leq 12 \mathrm{mo}$. & 47 & $18(10.8 \%)$ & $29(11.7 \%)$ & & \\
\hline 3- symptomatic - treatment > $12 \mathrm{mo}$. & 172 & $72(43.4 \%)$ & $100(40.3 \%)$ & & \\
\hline 4- asymptomatic - no treatment & 51 & 19 (11.5\%) & $32(12.9 \%)$ & & \\
\hline 5- asymptomatic - treatment $\leq 12 \mathrm{mo}$. & 16 & $7(4.2 \%)$ & $9(3.6 \%)$ & & \\
\hline 6- asymptomatic - treatment > 12 mo. & 80 & $20(12.0 \%)$ & $60(24.2 \%)$ & & \\
\hline Classification of outcome & 138 & & & $0.165^{* *}$ & \\
\hline 1- recovery within 3 years & 72 & $24(57.14 \%)$ & $48(50 \%)$ & & \\
\hline 2 - recovery between 3 and 5 years & 32 & $6(14.29 \%)$ & $26(27.08 \%)$ & & \\
\hline 3- no recovery at 5 years & 30 & $12(28.57 \%)$ & $18(18.75 \%)$ & & \\
\hline 4- death & 4 & $0(0 \%)$ & $4(4.17 \%)$ & & \\
\hline \multicolumn{6}{|l|}{ Genetic data } \\
\hline BTNL2 & 436 & & & $0.17^{* * *}$ & $0.39^{* * *}$ \\
\hline BTNL2 A/A & 201 & 89 (47.8\%) & $112(44.8 \%)$ & & \\
\hline BTNL2 A/G & 194 & $84(45.2 \%)$ & 110 (44.0\%) & & \\
\hline BTNL2 G/G & 41 & $13(7.0 \%)$ & 28 (11.2\%) & & \\
\hline
\end{tabular}

*Significant raw $p$-values are followed by corrected $p$-values (Bonferroni correction) in brackets

**Small "Death" category excluded

${ }^{* * *} \mathrm{G} / \mathrm{G}$ vs. $\mathrm{G} / \mathrm{A}+\mathrm{A} / \mathrm{A}$

patients from one family, and seven patients from another one). Most of the 303 patients with known ancestors' birth countries were European (78\%); the others were Caribbean or Sub-Saharan African (22\%). This distribution did not differ from that of the controls. Table 1 shows a comparison of patient epidemiological, clinical, and biological characteristics between sporadic and familial cases.

\section{Impact of disease type}

Univariate comparisons between sporadic and familial cases revealed no significant differences in terms of sex ratio, geographical origin, number of involved organs at diagnosis, distribution of chest X-ray stages at diagnosis, respiratory function tests, biological data, or smoking habits. Also, the incidence of Löfgren syndrome was not different between familial and sporadic cases $(17.8 \%$ vs. 
Table 2 Comparison of clinical characteristics according to the BTLN2 genotype (G/G vs. A/A plus G/A)

\begin{tabular}{|c|c|c|c|c|c|}
\hline \multirow[t]{2}{*}{ Data } & \multirow[t]{2}{*}{ Number } & \multicolumn{3}{|l|}{ BTNL2 } & \multirow[t]{2}{*}{ Univariate model raw $p$ value ${ }^{* * *}$} \\
\hline & & $\overline{\mathrm{A} / \mathrm{A}}$ & $\mathrm{G} / \mathrm{A}$ & $\mathrm{G} / \mathrm{G}$ & \\
\hline Epidemiological data & & & & & 0.59 \\
\hline Ethnicity & 292 & & & & \\
\hline European & 226 & $103(75.7 \%)$ & $104(80 \%)$ & $19(73.1 \%)$ & \\
\hline Caribbean or Sub-Saharan African & 66 & $33(24.3 \%)$ & $26(20 \%)$ & $7(26.9 \%)$ & \\
\hline \multicolumn{6}{|l|}{ Clinical data at diagnosis } \\
\hline Disease onset & 389 & & & & 0.91 \\
\hline Asymptomatic & 130 & $60(34.29 \%)$ & $59(33.15 \%)$ & $11(30.56 \%)$ & \\
\hline Symptomatic & 259 & $115(65.71 \%)$ & $119(66.85 \%)$ & $25(69.44 \%)$ & \\
\hline Löfgren syndrome & 368 & & & & $0.042[0.42]$ \\
\hline Yes & 58 & $25(14.71 \%)$ & $32(19.39 \%)$ & $1(3.03 \%)$ & \\
\hline No & 310 & $145(85.29 \%)$ & $133(80.61 \%)$ & $32(96.97 \%)$ & \\
\hline Number of organs involved & 397 & & & & 0.074 \\
\hline 1 & 152 & $70(38.46 \%)$ & $73(41.01 \%)$ & $9(24.32 \%)$ & \\
\hline 2 & 115 & $55(30.22 \%)$ & $49(27.53 \%)$ & $11(29.73 \%)$ & \\
\hline 3 & 66 & $29(15.93 \%)$ & $33(18.54 \%)$ & $4(10.81 \%)$ & \\
\hline$\geq 4$ & 64 & $28(15.39 \%)$ & $23(12.92 \%)$ & $13(35.14 \%)$ & \\
\hline Organs involved & 397 & & & & 0.082 \\
\hline Lungs only & 143 & $68(37.36 \%)$ & $67(37.64 \%)$ & $8(21.62 \%)$ & \\
\hline Lungs and Eyes & 52 & $23(12.64 \%)$ & $20(11.24 \%)$ & $9(24.33 \%)$ & \\
\hline Lungs and Skin & 20 & $11(6.04 \%)$ & $8(4.49 \%)$ & $1(2.7 \%)$ & \\
\hline Other sites & 182 & $80(43.96 \%)$ & $83(46.63 \%)$ & $19(51.35 \%)$ & \\
\hline X-ray staging & 432 & & & & 0.26 \\
\hline 0 & 57 & $25(12.5 \%)$ & $26(13.47 \%)$ & $6(15.38 \%)$ & \\
\hline 1 & 158 & 77 (38.5\%) & 65 (33.68\%) & $16(41.03 \%)$ & \\
\hline 2 & 149 & $67(33.5 \%)$ & $68(35.23 \%)$ & $14(35.9 \%)$ & \\
\hline 3 & 47 & $24(12 \%)$ & $22(11.4 \%)$ & $1(2.56 \%)$ & \\
\hline 4 & 21 & $7(3.5 \%)$ & $12(6.22 \%)$ & $2(5.13 \%)$ & \\
\hline \multicolumn{6}{|l|}{ PFT at first visit } \\
\hline TLC (\%) & & & & & 0.098 \\
\hline$<80 \%$ & 47 & $23(24.47 \%)$ & $22(23.91 \%)$ & $2(9.52 \%)$ & \\
\hline$\geq 80 \%$ & 160 & $71(75.53 \%)$ & 70 (76.09\%) & $19(90.48 \%)$ & \\
\hline \multicolumn{6}{|l|}{ Pattern of disease course } \\
\hline SCAC & 398 & & & & 0.83 \\
\hline 1- symptomatic - no treatment & 46 & $21(11.6 \%)$ & $22(12.1 \%)$ & $3(8.3 \%)$ & \\
\hline 2- symptomatic - treatment $\leq 12 \mathrm{mo}$. & 47 & $19(10.5 \%)$ & $22(12.1 \%)$ & $6(16.7 \%)$ & \\
\hline 3- symptomatic - treatment > 12 mo. & 166 & $75(41.4 \%)$ & $74(40.9 \%)$ & $17(47.2 \%)$ & \\
\hline 4- asymptomatic - no treatment & 48 & $19(10.5 \%)$ & $26(14.4 \%)$ & $3(8.3 \%)$ & \\
\hline 5- asymptomatic - treatment $\leq 12 \mathrm{mo}$. & 14 & $6(3.3 \%)$ & $7(3.9 \%)$ & $1(2.8 \%)$ & \\
\hline 6- asymptomatic - treatment > 12 mo. & 77 & $41(22.7 \%)$ & $30(16.6 \%)$ & $6(16.7 \%)$ & \\
\hline Classification of outcome & 137 & & & & $0.015[0.14]^{* * *}$ \\
\hline 1- recovery within 3 years & 72 & $29(52.73 \%)$ & $36(52.17 \%)$ & $7(53.85 \%)$ & \\
\hline 2- recovery between 3 and 5 years & 32 & $9(16.36 \%)$ & $17(24.64 \%)$ & $6(46.15 \%)$ & \\
\hline 3 - no recovery at 5 years & 29 & $15(27.27 \%)$ & $14(20.29 \%)$ & $0(0 \%)$ & \\
\hline 4- death & 4 & $2(3.64 \%)$ & $2(2.9 \%)$ & $0(0 \%)$ & \\
\hline
\end{tabular}

*Significant raw $p$-values are followed by corrected $p$-values (Bonferroni correction) in brackets

**Small "Death" category excluded

***G/G vs. $G / A+A / A$ 
$13.5 \%$, respectively). However, the age at diagnosis was lower in familial cases $(p=0.021$ after Bonferroni correction) and the combinations of organs involved at diagnosis were significantly different $(p=0.003$ after Bonferroni correction).

Sporadic cases needed treatment more often than familial cases ( $p=0.008$ after Bonferroni correction). Among treated patients, $52.3 \%$ of familial and $59.8 \%$ of sporadic cases received exclusively corticosteroids. Other treatments (methotrexate, azathioprine, aminoquinolines, or anti-TNF alpha) were given to $47.7 \%$ of familial and $40.2 \%$ of sporadic cases. The SCAC was significantly different between familial and sporadic cases $(p=0.0497$ after Bonferroni correction) but the classification of outcome did not show a significant difference.

A multivariate model was then constructed with the following variables assessed at diagnosis: age, sex, chest $\mathrm{X}$-ray stage, organs involved, and BTNL2 polymorphism. The model was run on the 390 patients without missing data (233 sporadic and 157 familial cases, the former being the reference). The OR estimates and their 95\% CIs were $0.81[0.69 ; 0.96]$ for age (per ten-year increment) and $0.73[0.45 ; 1.18]$ for sex (males vs. females). Considering an additive effect for ordinal variables and a dominant genetic model for BTNL2 polymorphism (GG being the wild-type homozygous genotype), the OR estimates were: $1.04[0.80 ; 1.34]$ for chest X-ray stage (per stage increment), 1.46 [0.62; 3.45] for BTNL2 (G/G vs. G/A plus A/ A), 1.13 [0.67; 1.88] for organs involved "lungs only", 0.47 [0.21; 1.08] for "lungs and eyes", 3.16 [1.05; 9.54] for "lungs and skin" ("other organs" being the reference). In agreement with the univariate analyses, familial cases were significantly younger at diagnosis than sporadic ones $(p=0.016)$ and the organs involved in familial cases were more often "lungs and skin" $(p=0.041)$.

\section{Impact of BTNL2}

In the control population $(n=430)$, the genotypes observed for SNP rs2076530 (normal allele vs. mutated variant A) were respectively 75 (17.4\%) G/G, 143 (33.2\%) G/A, and 212 (49.3\%) A/A. The relative distribution of genotype G/G vs. G/A plus A/A was significantly different between sarcoidosis cases and the control population (odds ratio, $\mathrm{OR}=2.02$; 95\% confidence interval, $\mathrm{CI}$ : [1.32-3.09]). The same comparison performed between familial and sporadic cases showed no statistically significant difference.

Table 2 shows that, in the whole population of patients, there is no correlation between BTNL2 polymorphism and the various clinical phenotypes, the SCAC, or the classification of outcome.

\section{Discussion}

The present study was based on clinical and genetic investigations in a nation-wide cohort of both familial and sporadic sarcoidosis cases. Comparisons between familial and sporadic cases showed some clinical differences but, mostly, the absence of difference in BTNL2 rs2076530 variant frequency. Moreover, the study found no genotype-phenotype correlation between BTNL2 and clinical phenotype, SCAC, or the classification of outcome.

Familial aggregation of sarcoidosis cases is already well known [14]; it raised the issues of predisposing genes and genotypes involved in a Mendelian inheritance of the clinical phenotype. Along with ACCESS [15], we assessed the clinical phenotypes and the outcomes in a large cohort of sarcoid patients comparing sporadic and familial cases. In agreement with the literature [16-19], we observed no difference in sex ratio or geographic origin between familial and sporadic cases. However, in contrast with other reports $[16,18,19]$, age at diagnosis was significantly lower in the present study familial cases. This observation suggests that diagnosing sarcoidosis in individuals closely related to index cases in predisposed families may be made earlier than in sporadic cases. A previous work [17] compared the clinical profiles of patients whose diagnosis was made incidentally with symptomatic cases but could not conclude because of small sample sizes. In agreement with Sharma et al. [6], we found a difference between familial and sporadic cases regarding the disease onset (symptomatic vs. asymptomatic); this difference was statistically significant as per the raw $p$ value but not significant after Bonferroni correction.

In addition, in agreement with other studies [16, 17], we found no differences in terms of chest X-ray staging or number of organs involved at diagnosis between familial and sporadic cases but the combinations of organs involved at diagnosis was significantly different between the two groups in univariate analyses. Also, the multivariate analysis showed a significant difference between familial and sporadic cases regarding lungs and skin combination. According to Delaveri et al. [20] such an observation may be in relation with the genetic predisposing background. Finally, as also reported by Sharma et al. [16], familial and sporadic cases did not differ in terms of drugs used (corticosteroids alone vs. immunosuppressive drugs).

Several investigators have designed comprehensive scoring systems to assess the disease impact and outcome [3-8]. Two of them have integrated the need for more than a 12 -month treatment period $[4,6]$. In the present study, we found a significant difference between familial and sporadic cases in terms of disease progression patterns (as per the SCAC) [6] but only a trend toward a difference in the classification of outcome classification according to the duration of the disease. This may reflect a lack of power regarding the classification of outcome. Indeed, only 138 patients had a sufficient follow-up to be correctly classified, whereas 344 patients 
could be classified with SCAC. A retrospective study of patients with an isolated lung involvement and 6-144 months of follow-up [5] has identified four disease phenotypes. We cannot easily refer to this series because of the predominance, in our series, of a multi-organ involvement.

The BTNL2-related OR we found here is similar to previously reported ones $[2,8-10]$. However, our study adds the original findings that although BTNL2 polymorphism was strongly associated with the disease, its presence was not predictive of the development of a rather familial or rather sporadic case and not associated with the clinical phenotypes, the SCAC, or the outcome. This result differs from others that suggested that BTNL2 might be a predisposing factor for persistent or progressive sarcoidosis $[10,21,22]$. Our data may be interpreted in the light of the low OR of BTNL2 rs2076530 (=2) we found; that is, the BTNL2 gene is not an explanatory factor of disease inheritance. The role of the rs2076530 variant is probably part of a set of genetic and environmental factors associated with the risk of acquiring the disease.

Combined effects of HLA-DRB1/DBP1 haplotypes and the BTNL2 variant have been previously reported [23, 24]. Here, we cannot exclude that the BTNL2-sarcoidosis association we observed is the consequence of gene proximity in the 6p21 area with a synergistic effect of some HLA class II haplotypes and the truncated form of BTNL2 on T-cell activation and proliferation process $[22,25]$. Actually, one limitation of the present study is the lack of extensive screening for HLA-DRB1/DPB1 in the patients. In familial cases, we have checked for SNPs within the HLADRB1/DPB1 genes in 9 unrelated index cases of familial sarcoidosis and found no common genotypes; this suggests that these index cases do not have a common ancestor and that there is no founder effect. We have also screened the full sequence of BTNL2 in a subset of 40 patients from 40 families and found no other variants than those described in the last version of the NCBI dbSNP database. Actually, we analysed the BTNL2 gene for other variants and found that the rs2076530 A/A variant genotype cosegregates with the rs2076520 synonymous V313V, rs28362679 missense S334L, and rs41441651 missense D336N polymorphisms and, to date, we cannot exclude that these polymorphisms may have a complementary role with that of rs2076530 in the malfunction of BTNL2. Taken together these data demonstrate clearly that, with an $\mathrm{OR}=2.0$, the rs2076530 splicing variant of BTNL2 should be considered as a genetic risk factor for sarcoidosis but cannot be considered as a major gene explaining a Mendelian inheritance in the familial form of the disease. As others, we suggest strongly that BTNL2 screening belongs to the panel of biomarkers in the diagnosis of sarcoidosis together with HLA class II haplotyping and further coming genes. Despite conflicting opinions, the 6p21.3 region carrying HLA and BTNL2 genes is still considered to be associated with an increased risk of TH1/TH17 diseases (tuberculosis, leprosy, beryllium disease, ulcerative colitis, or Crohn disease) [26-30]. Here, the BTNL2 rs2076530 splice variant could not distinguish sporadic from familial forms and we still have to understand pathways through which the truncated form of BTNL2 may be involved in the pathogenesis of sarcoidosis.

Sarcoidosis seems to be a multifactorial disease that involves various genetic and environmental pathogenic factors. To date, strong roles are suggested for different SNPs in various genes mostly identified by association studies: HLA-DP subregion, BTNL2, Annexin A11, and, more recently Toll-like receptors, coiled-coil domaincontaining protein $88 \mathrm{~B}$, Ataxin- $2 / \mathrm{SH} 2 \mathrm{~B}$ adapter protein 3 , interleukin IL12B, and Beta-mannosidase/Nuclear factor NF-kappa-B p105 subunit [8, 31-36]. More than ten genes might then be involved in the predisposition to sarcoidosis and next generation sequencing studies will probably provide new candidates for the molecular pathways of granuloma generation. Finally, sarcoidosis might not be a single disease entity but rather a reaction to various triggering events.

Because the present study data were collected from both prevalent and incident cases (to increase the number of familial cases and recoverable DNAs), two biases may be considered. Firstly, some data were missing because of their retrospective collection and others because the 28 centres might not have given the same number of visits or the same delays between visits to all patients. Secondly, ancestry data relied on the ancestors' birth countries and several patients had ancestors from distinct continents. However, BTNL2 polymorphism was shown linked to sarcoidosis regardless of ethnicity in Caucasian, Afro-American, and Japanese patients [37]. Lastly, we did not use the clinical outcome status (COS) of the WASOG Task Force [7] because the COS became available four years after the start of the present study.

\section{Conclusions}

This study is an original comparison of sarcoidosis phenotypes and genotypes between familial and sporadic cases in a very large cohort. Despite a significant difference in BTNL2 polymorphism between sarcoid patients and controls, the lack of correlations between polymorphism, inheritance, clinical phenotypes, and outcome argues against the consideration of this single genetic difference as a practical marker for patient classification or optimized individual patient management.

\section{Abbreviations}

BTNL2: Butyrophilin-like 2 (gene); Cl: Confidence interval; FEV1: Forced expiratory volume in one second; FVC: Forced vital capacity; OR: Odds ratio; SARCFAM: Sarcoïdose Familiale (study); SCAC: Sarcoid Clinical Activity Classification; SNP: Single-nucleotide polymorphism; TLC: Total lung capacity; WASOG: World Association for Sarcoidosis and Other Granulomatous Disorders 


\section{Acknowledgements}

The authors thank Juthier L, Ouaglal H, and Castaldi MH for their technical assistance and Jean Iwaz (Hospices Civils de Lyon) for the revision of the final versions of this manuscript.

The authors also thank the members of the GSF group: Gouita A (CHU Marseille Nord), Chanez P (CHU Marseille), Peyrat-Detis E and Prevot G (CHU Toulouse), Diab S (CHU Grenoble), Prieur F (CHU ST Etienne), LocatelliSanchez M, Gaillot-Drevon M, Kiakouama L, Broussolle C, Varron L, Charron A, Kuntz J, Ledoux K, Le Scanff MC, and Bouaziz (CHU Lyon Sud), Pavic M (CH Desgenettes Lyon), Ninet J and Cordier JF (CHU Lyon Est), Vincent M (CH ST Joseph-St Luc, Lyon), Coudurier M (CH Chambery), GAGNADOUX F (CHU Angers), Jounieaux F(CHU Lille), Terce G (CHU Lille), Diot P (CHU Tours), Marchand-AdamsS (CHU Tours), Morel H (CH ST Malo), Jouneau S (CHU Rennes), Olivier-Faivre L (CHU Dijon), Lacronique J (APHP, Hôpital Cochin), Juvin K (APHP, Hôpital Européen Georges Pompidou), Crestani B, Aubier M, Borie R, Roussel R and Chapelon Abric C (APHP, Hôpital Bichat), Hervier B, Piette JC, Janssens T, and Saadoun D (APHP, CH Pitié Salpêtrière), Nathan N and Clément A (APHP, CH Trousseau), Ducroix JP (CHU Amiens), Guillaumat $C$ and Watkin E (CH Sud Francilien), Freynet M, Naccache JM and Uzunhan Y (APHP, Hôpital Avicenne), and Limal N (APHP, Hôpital Henri Mondor).

\section{Funding}

The initial project ("Étude Clinique et Génétique des Formes Familiales de Sarcoïdose") was supported by the French Ministère des Affaires Sociales et de la Santé" (Projet Hospitalier de Recherche Clinique National: PHRC national 2008 No SP/AO 12/D5O604; PHRC national 2012 №12-027-0309) and by the Comité Français des Maladies Respiratoires ( ${ }^{\circ}$ DG2013-15KM). The project promoter is Hospices Civils de Lyon.

The funding bodies did not intervene in the study design, data collection and analysis, result interpretation, or drafting the manuscript.

\section{Availability of data and materials}

The data are available on request from the corresponding author.

\section{Authors' contributions}

Study design and monitoring: YP, AC, DI, PR, SL, and DV. Data collection: YP, AC, $\mathrm{DI}, \mathrm{VC}, \mathrm{DB}, \mathrm{HN}, \mathrm{PS}, \mathrm{LP}, \mathrm{GD}, \mathrm{NF}, \mathrm{CK}, \mathrm{BW}$, and DV. Genetic laboratory analyses: AC, SL, RL. Data analysis: PR, ME, and CB. Result interpretation and manuscript drafting: YP, AC, DI, PR, SL, VC, DB, HN, PS, LP, GD, NF, CK, B W, ME, CB, and DV. Approval of final manuscript: All authors.

\section{Competing interests}

The authors declare that they have no competing interests.

\section{Consent for publication}

Not applicable.

\section{Ethics approval and consent to participate}

SARCFAM study obtained Agreement № 914377 from the Commission Nationale de l'Informatique et des Libertés to collect clinical and genetic information. All included patients gave written informed consents for information collection and use. The genetic study on BTNL2 was performed in accordance with the recommendations of the French bioethic laws.

\section{Author details}

${ }^{1}$ Hospices Civils de Lyon, Centre Hospitalier Lyon Sud, Université Claude Bernard - Lyon 1, EA-7426, Lyon, France. ${ }^{2}$ Hospices Civils de Lyon, Hôpital Edouard Herriot, Plateforme de génétique moléculaire, CR-21076, Université Claude Bernard - Lyon 1, INSERM U1052, Lyon, France. ${ }^{3}$ AP-HP, Hôpital Européen Georges Pompidou, Service de Pneumologie, Centre de Compétence des maladies pulmonaires rares, Université René Descartes Paris 5, Paris, France. ${ }^{4}$ Hospices Civils de Lyon, Service de Biostatistique, Université Claude Bernard - Lyon 1, CNRS UMR 5558, Lyon, France. ${ }^{5}$ Hospices Civils de Lyon, Hôpital Lyon-Sud, Université Claude Bernard - Lyon1, INSERM U1052 - CNRS UMR5286, Lyon, France. ${ }^{6}$ Hospices Civils de Lyon, Hôpital Louis Pradel, Université Claude Bernard - Lyon 1, UMR 754, Lyon, France. ${ }^{7}$ AP-HP, Hôpital Avicenne, Université Paris13, EA2363, COMUE Sorbonne Paris Cité, Paris, France. ${ }^{8}$ Hospices Civils de Lyon, Hôpital Croix-Rousse, Université Claude Bernard - Lyon 1, Lyon, France. ${ }^{9}$ Hospices Civils de Lyon, Hôpital Edouard Herriot, Université Claude Bernard - Lyon 1, Lyon, France. ${ }^{10}$ Centre hospitalo-universitaire de Lille, Service de Pneumologie et
Immunoallergologie, Centre de Compétence Maladies Pulmonaires Rares, Université Lille 2, Lille, France. "1Université Claude Bernard Lyon 1 - EA-7426, 165 Chemin du Grand Revoyet, F-69495 Pierre Benite, France.

Received: 1 June 2016 Accepted: 21 November 2016

Published online: 03 December 2016

\section{References}

1. Valeyre D, Prasse A, Nunes H, Uzunhan Y, Brillet PY, Müller-Quernheim J. Sarcoidosis. Lancet. 2014;383:1155-67.

2. Lin Y, Wei J, Fan L, Cheng D. BTNL2 gene polymorphism and sarcoidosis susceptibility: a meta-analysis. PLoS ONE. 2015;10:e0122639.

3. Scadding JG. Prognosis of intrathoracic sarcoidosis in England. A review of 136 cases after five years' observation. BMJ. 1961;2:1165-72.

4. Wasfi YS, Rose CS, Murphy JR, et al. A new tool to assess sarcoidosis severity. Chest. 2006;129:1234-45.

5. Rodrigues SC, Rocha NA, Lima MS, Arakaki JS, Coletta EN, Ferreira RG, et al. Factor analysis of sarcoidosis phenotypes at two referral centers in Brazil. Sarcoidosis Vasc Diffuse Lung Dis. 2011;28:34-43.

6. Prasse A, Katic C, Germann M, Buchwald A, Zissel G, Müller-Quernheim J. Phenotyping sarcoidosis from a pulmonary perspective. Am J Respir Crit Care Med. 2008;177:330-6.

7. Baughman RP, Nagai S, Balter M, et al. Defining the clinical outcome status (COS) in sarcoidosis: results of WASOG Task Force. Sarcoidosis Vasc Diffuse Lung Dis. 2011;28:56-64.

8. Valentonyte R, Hampe J, Huse K, Rosenstiel P, Albrecht M, Stenzel A et al. Sarcoidosis is associated with a truncating splice site mutation in BTNL2. Nat Genet. 2005;37:57-64.

9. Rybicki BA, Walewski JL, Maliarik MJ, Kian H, lannuzzi MC, ACCESS Research Group. The BTNL2 gene and sarcoidosis susceptibility in African and Whites. Am J Human Genet. 2005;77:491-9.

10. Li Y, Wollnik B, Pabst S, Lennarz M, Rohmann E, Gillissen A, et al. BTNL2 gene variant and sarcoidosis. Thorax. 2006;61:273-4.

11. American Thoracic Society, European Respiratory Society, World association of Sarcoidosis and Other Granulomatous Disorders. Statement on sarcoidosis: joint statement of the American Thoracic Society (ATS), European Respiratory Society (ERS), World association of Sarcoidosis and Other Granulomatous Disorders (WASOG) adopted by the ATS Board of Directors and by the ERS Executive Committee, February 1999. Am J Respir Crit Care Med. 1999;160:736-55.

12. Vazquez Al, Bates DM, Rosa GJ, Gianola D, Weigel KA. Technical note: An R package for fitting generalized linear mixed models in animal breeding. J Anim Sci. 2010;88:497-504

13. Shaffer JP. Multiple Hypothesis Testing. Ann Rev Psychol. 1995;46:561-84.

14. Rybicki BA, lannuzzi MC, Frederick MM, Thompson BW, Rossman MD, Bresnitz EA, et al. ACCESS Research Group. Familial aggregation of sarcoidosis. A case-control etiologic study of sarcoidosis (ACCESS). Am J Respir Crit Care Med. 2001;164:2085-91.

15. Rossman MD, Kreider ME. Lesson learned from ACCESS. Proc Am Thorac Soc. 2007:4:453-6.

16. Sharma OP, Neville E, Walker AN, James DG. Familial sarcoidosis: a possible genetic influence. Ann N Y Acad Sci. 1976;278:386-400.

17. Neville E, Walker AN, James DG. Prognostic factors predicting the outcome of sarcoidosis: an analysis of 818 patients. Q J Med. 1983;52:525-33.

18. Brennan NJ, Crean P, Long JP, Fitzgerald MX. High prevalence of familial sarcoidosis in an Irish population. Thorax. 1984;39:14-8.

19. Nassif X, Valeyre D, Loiseau A, Battesti JP. Familial sarcoidosis. Apropos of 22 families. Ann Med Interne (Paris). 1985;136:611-4.

20. Delaveri A, Rapti A, Poulou M, Fylaktou E, Tsipi M, Roussos C, et al. BTNL2 gene SNPS as a contributing factor to sarcoidosis pathogenesis in a cohort of Greek patients. Meta Gene. 2014;2:619-30.

21. Wijnen PA, Voorter CE, Nelemans PJ, Verschakelen JA, Bekers O, Drent M. Butyrophilin-like 2 in pulmonary sarcoidosis: a factor for susceptibility and progression. Hum Immunol. 2011;72:342-7.

22. Wennerström A, Pietinalho A, Lasota J, Salli K, Surakka I, Seppänen M, et al. Major histocompatibility complex class II and BTNL2 associations in sarcoidosis. Eur Respir J. 2013:42:550-3.

23. Grunewald J, Brynedal B, Darlington P, Nisell M, Cederlund K, Hillert J, et al. Different HLA-DRB1 allele distributions in distinct clinical subgroups of sarcoidosis patients. Respir Res. 2010;11:25. 
24. Sato H, Grutters JC, Pantelidis P, Mizzon AN, Ahmad T, Van Houte AJ, et al. HLA-DQB1 0201. A marker for good prognosis in British and Dutch patients with sarcoidosis. Am J Respir Cell Mol Biol. 2002;27:406-12.

25. Sato H, Woodhead FA, Ahmad T, Grutters JC, Spagnolo P, van den Bosch $J \mathrm{M}$, et al. Sarcoidosis HLA class II genotyping distinguishes differences of clinical phenotype across ethnic groups. Hum Mol Genet. 2010;19:4100-11.

26. Johnson CM, Traherne JA, Jamieson SE, Tremelling M, Bingham S, Parkes M, et al. Analysis of the BTNL2 truncating splice siter mutation in tuberculosis, leprosy and Crohn's disease. Tissue Antigens. 2007;69:236-41.

27. Mochida A, Kinouchi Y, Negoro K, Takahashi S, Takagi S, Nomura E, et al. Butyrophilin-like 2 gene is associated with ulcerative colitis in the Japanese under strong linkage disequilibrium with HLA-DRB1 1502. Tissue Antigens. 2007;70:128-35.

28. Sato H, Spagnolo P, Silveira L, Welsh KI, du Bois RM, Newman LS, et al. BTNL2 allele associations with chronic beryllium disease in HLA-DPB1 GLU69-negative individuals. Tissue Antigens. 2007;70:480-6.

29. Ali S, Chopra R, Aggarwal S, Srivastava AK, Kalaiarasan P, Malhotra D, et al. Association of variants in, BAT1-LTA-TNF-BTNL2 genes within 6p21-3 region show graded risk to leprosy in unrelated cohorts of Indian population. Human Genet. 2012;131:703-16.

30. Möller M, Kwiatkowski R, Nebel A, van Helden PD, Hoal EG, Schreiber S. Allelic variation in BTNL2 and susceptibility to tuberculosis in a South African population. Microbes Infect. 2007;9:522-8.

31. Schürmann M, Bein G, Kirsten D, Schlaak M, Müller-Quernheim J, Schwinger E. HLA-DQB1 and HLA-DPB1 genotypes in familial sarcoidosis. Respir Med. 1998:92:649-52

32. Hofmann S, Franke A, Fisher A, Jacobs G, Nothnagel M, Gaede Kl, et al. Genome-wide association study identifies ANXA11 as a new susceptibility locus for sarcoidosis. Nat Genet. 2008;40:1103-6.

33. Veltkamp M, van Moorsel CH, Rijkers GT, Ruven HJ, Grutters JC. Genetic variation in the Toll-like receptor gene cluster (TLR10-TLR1-TLR6) influences disease course in sarcoidosis. Tissue Antigens. 2012;79:25-32.

34. Fischer A, Schmid B, Ellinghaus D, Nothnagel M, Gaede Kl, Schürmann M, et al. A novel sarcoidosis risk locus for Europeans on chromosome 11q13.1. Am J Respir Crit Care Med. 2012;186:877-85.

35. Fischer A, Ellinghaus D, Nutsua M, Hofmann S, Montgomery CG, lannuzzi $M C$, et al. Identification of immune-relevant factors conferring sarcoidosis genetic risk. Am J Respir Crit Care Med. 2015;192:727-36.

36. Smith G, Brownell I, Sanchez M, Prystowsky S. Advances in the genetics of sarcoidosis. Clin Genet. 2008;73:401-12.

37. Suzuki H, Ota M, Meguro A, Katsuyama Y, Kawagoe T, Ishihara M, et al. Genetic characterization and susceptibility for sarcoidosis in Japanese patients: risk factors of BTNL2 gene polymorphisms and HLA class II alleles. Invest Ophtalmo Vis Sci. 2012;53:7109-15.

\section{Submit your next manuscript to BioMed Central and we will help you at every step:}

- We accept pre-submission inquiries

- Our selector tool helps you to find the most relevant journal

- We provide round the clock customer support

- Convenient online submission

- Thorough peer review

- Inclusion in PubMed and all major indexing services

- Maximum visibility for your research

Submit your manuscript at www.biomedcentral.com/submit
Biomed Central 